\title{
Sources of isocyanic acid (HNCO) indoors: a focus on cigarette smoke
}

\author{
Rachel F. Hems, Chen Wang, Douglas B. Collins, Shouming \\ Zhou, Nadine Borduas-Dedekind, Jeffrey A. Siegel, Jonathan P.D. \\ Abbatt
}

Version Post-print/Accepted Manuscript

Citation Hems, R.F., Wang, C., Collins, D.B., Zhou, S., Borduas-Dedekind, N., (published version) Siegel, J.A., Abbatt, J.P.D., 2019. Sources of isocyanic acid (HNCO) indoors: a focus on cigarette smoke. Environ. Sci.: Processes Impacts, 21, 1334. https://doi.org/10.1039/C9EM00107G.

How to cite TSpace items

Always cite the published version, so the author(s) will receive recognition through services that track citation counts, e.g. Scopus. If you need to cite the page number of the author manuscript from TSpace because you cannot access the published version, then cite the TSpace version in addition to the published version using the permanent URI (handle) found on the record page.

This article was made openly accessible by $U$ of $T$ Faculty. Please tell us how this access benefits you. Your story matters. 
1 Sources of isocyanic acid (HNCO) indoors: a focus on cigarette smoke

2 Rachel F. Hems,${ }^{\dagger}$ Chen Wang, ${ }^{\dagger}$ Douglas B. Collins, ${ }^{\dagger}$ Shouming Zhou, ${ }^{\dagger}$ Nadine Borduas-

3 Dedekind, ${ }^{\dagger}$ Jeffrey A. Siegel, ${ }^{\dagger}$ Jonathan P.D. Abbatt $* \dagger$

$4 \quad$ Department of Chemistry, University of Toronto, 80 St. George Street, Toronto, Ontario M5S

53 H6, Canada.

6 Department of Civil and Mineral Engineering, University of Toronto, 35 Street George Street,

7 Toronto, Ontario M5S 1A4, Canada.

$8{ }^{\ddagger}$ Department of Chemistry, Bucknell University, 1 Dent Drive, Lewisburg, PA 17837, USA.

9

\section{Abstract}

The sources and sinks of isocyanic acid (HNCO), a toxic gas, in indoor environments are largely uncharacterized. In particular, cigarette smoke has been identified as a significant source. In this study, controlled smoking of tobacco cigarettes was investigated in both an environmental chamber and a residence in Toronto, Canada using an acetate-CIMS. The HNCO emission ratio from side-stream cigarette smoke was determined to be $2.7( \pm 1.1) \times 10^{-3} \mathrm{ppb} \mathrm{HNCO} / \mathrm{ppb} \mathrm{CO}$. Side-stream smoke from a single cigarette introduced a large pulse of HNCO to the indoor environment, increasing the HNCO mixing ratio by up to a factor of ten from background conditions of $0.15 \mathrm{ppb}$. Although there was no evidence for photochemical production of HNCO from cigarette smoke in the residence, it was observed in the environmental chamber via oxidation by the hydroxyl radical $\left(1.1 \times 10^{7}\right.$ molecules $\left.\mathrm{cm}^{-3}\right)$, approximately doubling the HNCO mixing ratio after 30 minutes of oxidation. Oxidation of cigarette smoke by $\mathrm{O}_{3}(15 \mathrm{ppb}=4.0 \times$ $10^{17}$ molecules $\mathrm{cm}^{-3}$ ) and photo-reaction with indoor fluorescent lights did not produce HNCO. By studying the temporal profiles of both $\mathrm{HNCO}$ and $\mathrm{CO}$ after smoking, it is inferred that gas-tosurface partitioning of HNCO acts as an indoor loss pathway. Even in the absence of smoking, the indoor HNCO mixing ratios in the Toronto residence were elevated compared to concurrent outdoor measurements by approximately a factor of two. 


\section{Introduction}

Isocyanic acid (HNCO) is a toxic gas often measured at elevated concentrations in biomass burning plumes, ${ }^{1-7}$ emissions from diesel and gasoline vehicles, ${ }^{8-11}$ and in industrial processes such as certain welding applications and polyurethane processing, ${ }^{12-15}$ but HNCO has also been detected at trace levels in ambient air. ${ }^{16-19}$ Along with these primary sources, there is evidence of a secondary source driven by atmospheric photochemistry. ${ }^{6,18-20}$ Laboratory and computational chemistry studies have identified amines and amides as classes of compounds that act as precursors to photochemical production of $\mathrm{HNCO} .^{21-25}$

However, except for measurements in selected industrial settings, measurements of HNCO in indoor environments have not been reported. ${ }^{26}$ Its sources and sinks indoors are largely unknown and cannot be approximated from outdoor behaviour due to the different types of sources, large surface area to volume ratio of indoor environments, differing oxidant concentrations, and often orders of magnitude lower actinic flux. Given the large amount of time people spend indoors, understanding the behaviour of $\mathrm{HNCO}$ is necessary to determine the extent of occupant exposure.

Furthermore, emissions of HNCO from tobacco cigarette smoke, a form of biomass burning often carried out indoors, have not been investigated. Not only does cigarette smoke have the potential to be a significant primary source of $\mathrm{HNCO},{ }^{4}$ the smoke may also act as a secondary source. Cigarette smoke contains reactive precursors, such as nicotine and formamide, ${ }^{23,24}$ which can produce $\mathrm{HNCO}$ upon reaction with hydroxyl radicals. Semi-volatile components of cigarette smoke partition to indoor surfaces ${ }^{27,28}$ where they can undergo reaction or can be re-emitted to the gas phase after the initial smoking event has ended. Therefore, partitioning processes have the potential to impact indoor $\mathrm{HNCO}$ concentrations over a longer timescale than during a single smoking event.

This study quantifies the primary emission and secondary oxidative production of HNCO indoors, with a specific focus on side-stream cigarette smoke. Laboratory environmental chamber measurements of cigarette smoke are used to determine the HNCO emission ratio and explore the conditions under which secondary $\mathrm{HNCO}$ can be produced. Oxidation by ozone, hydroxyl radical, and photo-reaction under indoor fluorescent light were examined. We 
complement the chamber studies with the first quantitative, real-time measurements of HNCO in an indoor environment which were conducted at a residence in Toronto, Canada in November 2016 during cigarette smoking, candle burning, use of a gas stove, and under background conditions. During the measurement campaign, concurrent indoor and outdoor measurements were undertaken to isolate the indoor sources of HNCO. The measurements in the residence extend the environmental significance of the chamber studies.

\section{Experimental}

\section{Cigarette Burning Measurements}

Laboratory measurements were conducted in a $1 \mathrm{~m}^{3}$ Teflon environmental chamber surrounded by 16 UV-B light bulbs (or 16 indoor fluorescent light bulbs), as described by Wang et al. ${ }^{29}$ Side-stream smoke released from the end of a research grade tobacco cigarette (1R6F, Kentucky Reference Cigarette, Center for Tobacco Reference Products at University of Kentucky), associated with a 2 -second puff using standard smoking procedures, ${ }^{30}$ was injected into the chamber for 15 seconds. Research grade cigarettes were used as an international standard that can be compared to other scientific studies and to avoid variation that may occur within individual tobacco manufacturers. Continuous oxidation of the smoke by $\mathrm{OH}$ radical in steadystate $\left(1.1 \times 10^{7}\right.$ molecules $\left.\mathrm{cm}^{-3}\right)$, an injection of ozone $\left(15 \mathrm{ppb}_{\mathrm{v}}=4.0 \times 10^{17}\right.$ molecules $\left.\mathrm{cm}^{-3}\right)$, and photolysis by indoor fluorescent lights were investigated in these experiments as potential secondary sources of HNCO. Experiments were carried out under both dry and humid conditions (RH $<5 \%$ and $\sim 50 \%$ ). ${ }^{29}$ The reported data includes both humidity conditions since no substantial differences in HNCO production were observed. The effects of oxidation of side-stream cigarette smoke on particulate matter concentration and size, as well as $\mathrm{NO}_{\mathrm{x}}$ and $\mathrm{CO}$ emissions have been reported by Wang et al. using the same setup. ${ }^{29}$

Indoor measurements were conducted from November 11 - 19, 2016 in an inhabited, previously non-smoking, semi-detached residence in Toronto, Canada, as described in detail in Collins et $a l{ }^{31}$ The two non-smoking inhabitants used the sampling areas and cooked infrequently during the study period and overall had minimal impact on the HNCO measurements. The home had an average air change rate of $0.19-0.74 \mathrm{~h}^{-1}$ and an approximate interzonal mixing rate between the kitchen (where combustion experiments took place) and the rest of the home of $1.4 \mathrm{~h}^{-1}$, as 
reported by Collins et al. ${ }^{31}$ The forced-air recirculating system operated continuously throughout the study period to promote mixing in the home. The indoor gas phase composition was sampled online switching between three sites at the house ( 2 indoor and 1 outdoor) at 5-minute intervals: the kitchen, outside, and (during the first half of the study) at the air return vent. The range of relative humidity $(\mathrm{RH})$ and temperature measured at the kitchen location were reported by Collins et al. ${ }^{31}$ The average RH in the kitchen was $34 \%$ and average temperature was $25^{\circ} \mathrm{C}$. Every hour, zero air (Air grade zero 0.1; Linde [Canada], Inc.) was measured for 2.5 minutes to determine instrumental background concentrations. Multiple combustion experiments were carried out throughout the measurement period, including candle burning, use of the gas stove, and cigarette smoking. Six cigarette smoking experiments were measured in the Toronto residence over the course of two days. Side-stream smoke from research grade cigarettes (1R6F, Kentucky Reference Cigarette, Center for Tobacco Reference Products at University of Kentucky) was emitted into the kitchen, in close proximity to the sampling inlet, using a custombuilt smoking machine controlled with LabView software (National Instruments). A standard smoking protocol was used, ${ }^{30}$ which included a 2 second "puff" (pulling a flow of $1.05 \mathrm{~L} \mathrm{~min}^{-1}$ ) followed by a period of 58 seconds where the cigarette was allowed to burn. It took approximately 4 puffs or 4.5 minutes to complete the burning of the cigarette.

\section{Quad-CIMS}

An acetate quadrupole-chemical ionization mass spectrometer (quad-CIMS) was used to measure $\mathrm{HNCO}$ during the targeted laboratory experiments in the environmental chamber. This instrument has been described previously in detail. ${ }^{32}$ In brief, the reagent ion was generated by flowing $20 \mathrm{sccm}$ of $\mathrm{N}_{2}$ (Nitrogen Grade 4.8; Linde [Canada], Inc.) over a glass tube containing acetic anhydride (Sigma-Aldrich) at room temperature. This flow was subsequently mixed with a $2 \mathrm{~L} / \mathrm{min} \mathrm{N}_{2}$ dilution flow and passed through a ${ }^{210}$ Po radioactive source (NRD, P-2031). The acetate reagent ion primarily ionizes analytes by proton abstraction, where analytes are detected as their $[\mathrm{M}-\mathrm{H}]]^{-}$ions, however other acetate ionization mechanisms have also been identified recently. ${ }^{33}$ Data was collected every 6 seconds under selected ion mode with a custom-written program based on LabView software (National Instruments). It was assumed that HNCO was the only species present at $\mathrm{m} / \mathrm{z} 42$ and that there were no interfering isobaric species. CIMS measurements with a higher mass resolving power (ToF-CIMS, described below) from the 
indoor measurement campaign indicated that $\mathrm{HNCO}$ was indeed the dominant species at its nominal $m / z$. Details on HNCO calibration are provided in section S1.

\section{High Resolution ToF-CIMS}

An acetate time-of-flight chemical ionization mass spectrometer (ToF-CIMS, Aerodyne Research Inc.) was deployed for online measurement of gaseous acids in the Toronto residence. This instrument has been described previously ${ }^{34-38}$ and will be briefly discussed here. The acetate reagent ion was generated by a flow of $40 \mathrm{sccm}$ ultrahigh-purity (UHP) $\mathrm{N}_{2}$ (UHP Zero Nitrogen Generator, Parker Balston) through the headspace of acetic anhydride (Sigma-Aldrich) in a stainless-steel bottle at room temperature, which was then diluted by a flow of $2.2 \mathrm{~L} / \mathrm{min}$ UHP $\mathrm{N}_{2}$. The reagent ion flow was ionized by a ${ }^{210}$ Po radioactive cell (NRD, P-2021) at a flow of 2 $\mathrm{L} / \mathrm{min}$ (set by a critical orifice). The IMR region was pressure controlled and set to $100 \pm 2 \mathrm{mbar}$ and the SSQ region was set to $2.7 \pm 0.3$ mbar. The CIMS was operated in a strong-field mode where the dominant reagent ion was the acetate ion, with the [acetate + acetic acid] ion cluster to acetate ion ratio at approximately 0.001 . The mass spectrometer was operated in $\mathrm{V}$-mode with data acquired every $2 \mathrm{~s}$. Tofware (Tofwerk, AG and Aerodyne Research Inc. Version 2.5.7) on Igor Pro (WaveMetrics Inc. Version 6.37) was used for raw data processing. The instrument had a mass accuracy of $\pm 5 \mathrm{ppm}$ and mass resolving power of $3000-4000$ over the relevant $\mathrm{m} / \mathrm{z}$ range. $\mathrm{HNCO}$ was detected as an anion $\left(\mathrm{NCO}^{--}\right)$at $\mathrm{m} / z$ 42.00. Offline calibration of the ToFCIMS was completed in the laboratory, as described in the supporting information section S1. Further details of the data analysis and limit of detection determination are provided in section S2. The limit of detection for the HNCO measurement was determined to be $0.02 \mathrm{ppb}$. The absolute uncertainty in the HNCO measurement was estimated to be $\pm 20 \%$.

Carbon monoxide (CO) was measured as a non-reactive gas, directly emitted in the cigarette side-stream smoke using a Thermo Scientific Model 48i (details in Collins et al. ${ }^{31}$ ). CO was used to determine the cigarette emission ratio, as well as to compare to the loss rate of HNCO after the cigarette was extinguished. For comparison to $\mathrm{CO}$ measurements, HNCO data was averaged to 1-minute intervals to be on an equivalent time base.

Results and Discussion

\section{Laboratory measurements of primary and secondary HNCO production}


Primary emissions from side-stream cigarette smoke were investigated in an environmental chamber. HNCO was reproducibly emitted during cigarette smoking, reaching ppb levels in the chamber. The emission ratio from the side-stream cigarette smoke is reported as the ratio of HNCO to CO (Table 1). An emission ratio of $2.7( \pm 1.1) \times 10^{-3} \mathrm{ppb} \mathrm{HNCO} / \mathrm{ppb} \mathrm{CO}$ was experimentally determined from 11 distinct cigarette emission experiments. This measurement falls within the range of $\mathrm{HNCO}$ emission ratios determined previously from other types of biomass burning smoke from representative south-western and south-eastern United States vegetation studied at the Fire Sciences Laboratory (Missoula, Montana) in $2009^{2}$ and in 2016, as part of the FIREX campaign ${ }^{39}$ (Table 1). The emission ratio variation between biomass burning sourses is likely due to different burning conditions (eg. smoldering vs. flaming) and fuel composition (tobacco vs. wood vs. leaf litter).

Table 1. Emission ratios of HNCO from side-stream cigarette smoke and biomass burning smoke. Error is reported as 1 standard deviation.

\begin{tabular}{|l|l|}
\hline Source & Emission Ratio (ppb HNCO/ppb CO) \\
\hline $\begin{array}{l}\text { Side-stream cigarette smoke - Chamber } \\
\text { Experiment (this study, } \mathrm{n}=11)\end{array}$ & $2.7( \pm 1.1) \times 10^{-3}$ \\
\hline $\begin{array}{l}\text { Side-stream cigarette smoke- Toronto } \\
\text { Residence (this study, } \mathrm{n}=6)\end{array}$ & $2.0( \pm 0.6) \times 10^{-3}$ \\
\hline $\begin{array}{l}\text { Biomass burning - Fire Sciences } \\
\text { Laboratory (2009) }\end{array}$ & $0.76( \pm 0.25) \times 10^{-3}$ \\
\hline Biomass burning - FIREX 2016 & $4.6( \pm 2.5) \times 10^{-3}$ \\
\hline
\end{tabular}

Subsequent experiments in the environmental chamber investigated the secondary production of HNCO from side-stream cigarette smoke. Conditions that were investigated included photoreaction by indoor fluorescent light, and oxidation by $\mathrm{O}_{3}$ and $\mathrm{OH}$ radical. $\mathrm{HNCO}$ was only observed to increase upon $\mathrm{OH}$ oxidation of the cigarette smoke. A representative cigarette smoke $\mathrm{OH}$ oxidation experiment (Figure 1A), shows that $\mathrm{HNCO}$ increases almost immediately following generation of $\mathrm{OH}$ radicals in the chamber (at elapsed time $=0$ minutes). Note that data are presented as the ratio of $\mathrm{HNCO}$ to $\mathrm{CO}$ to account for dilution in the chamber over time, and they are normalized to the initial $[\mathrm{HNCO}] /[\mathrm{CO}]$ ratio to account for variation in primary cigarette 
emissions. The $\mathrm{HNCO} / \mathrm{CO}$ ratio continued to increase linearly throughout the duration of the experiment (>90 minutes). This consistent increase indicates that there are enough precursor compounds in the cigarette smoke to continue to produce $\mathrm{HNCO}$ even after extensive oxidation. Since $\mathrm{HNCO}$ is not a first-generation product from nicotine $\mathrm{OH}$ oxidation ${ }^{40}$ and $\mathrm{OH}$ radical reaction with $\mathrm{HNCO}$ itself is very slow, ${ }^{41,42}$ it is not surprising that its concentration continued to increase over the course of the reaction.

As $\mathrm{OH}$ was generated by UV photolysis of $\mathrm{H}_{2} \mathrm{O}_{2}$, the direct photolysis of cigarette smoke by UV-B light was also investigated (omitting $\mathrm{H}_{2} \mathrm{O}_{2}$ from the chamber preparation). The $\mathrm{HNCO} / \mathrm{CO}$ ratio was observed to increase during UV-B exposure over the experimental period (Figure 1A) but contributed to less than $30 \%$ of the increase observed during $\mathrm{OH}$ oxidation. It is possible that photolysis of the smoke components generates $\mathrm{OH}$ radicals at lower concentrations, leading to the production of HNCO. While this is an interesting observation of secondary HNCO production, the intensity of UV-B light is much lower indoors than measured in the chamber, ${ }^{29}$ by at least an order of magnitude. In addition, HNCO production was not observed to occur with exposure to fluorescent lights, relevant to the indoor environment.

Figure 1B shows the percent increase of $\mathrm{HNCO}$ after 30, 60, and 90 minutes had elapsed, compared to 0 minutes, for each of the investigated conditions. As discussed, $\mathrm{O}_{3}$ oxidation and indoor fluorescent light exposure had no quantifiable impact on generating secondary HNCO and their percent increase remained at $0 \%$. After 30 minutes of $\mathrm{OH}$ oxidation, the $\mathrm{HNCO} / \mathrm{CO}$ ratio had approximately doubled (percent increase $=109 \%$ ) and by 90 minutes of reaction the $\mathrm{HNCO} / \mathrm{CO}$ ratio had increased by $290 \%$. This clear increase above background demonstrates the potential for a secondary source of $\mathrm{HNCO}$ through $\mathrm{OH}$ oxidation of cigarette smoke.

The $\mathrm{OH}$ concentration used in the chamber, on the order of $10^{7}$ molecule $\mathrm{cm}^{-3}$, is higher than would be typically expected indoors (on the order of $10^{5}$ molecule $\mathrm{cm}^{-3}$ ). ${ }^{43,44}$ However, high concentrations do arise with high nitrous acid (HONO) photolysis ${ }^{45}$ or during specific activities such as surface cleaning and use of an air cleaning device. ${ }^{44}$ Even with a factor of 10 lower $\mathrm{OH}$ concentration, doubling of the $\mathrm{HNCO} / \mathrm{CO}$ ratio observed in 30 minutes in the chamber would translate to a doubling in 300 minutes (5 hours) which can be significant within a poorly ventilated indoor environment. 

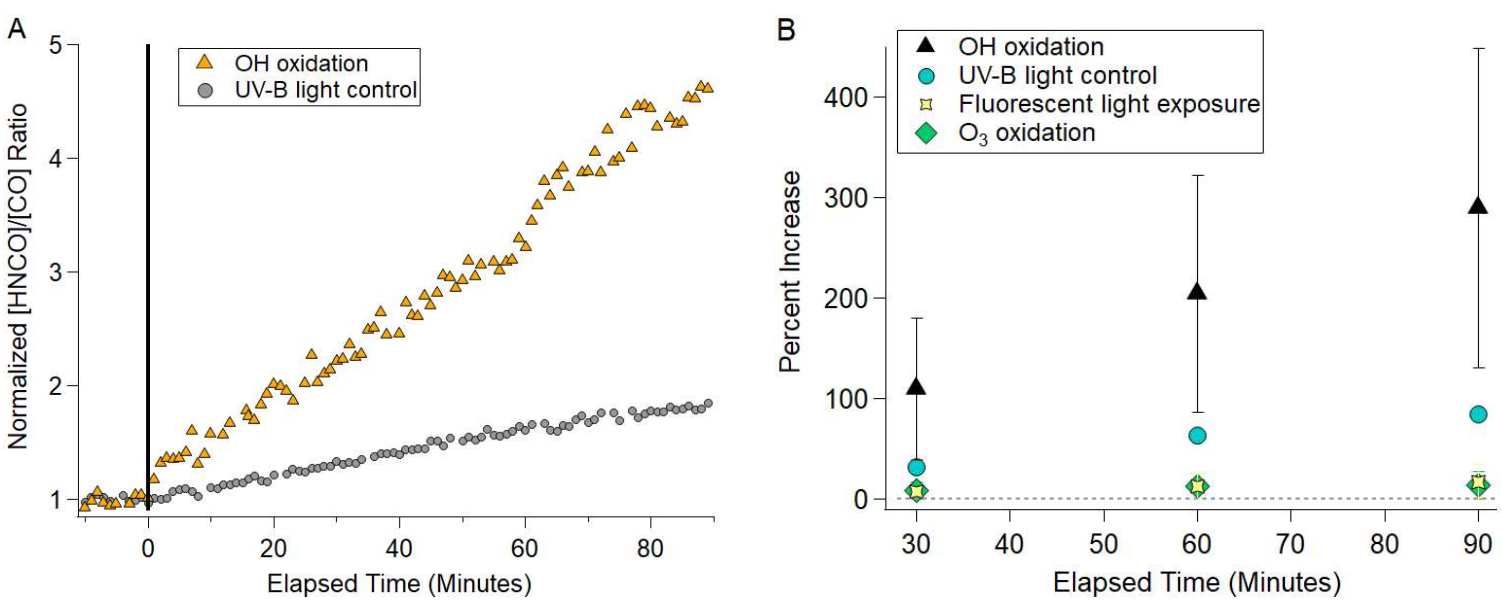

197

Figure 1. (A) Ratio of $[\mathrm{HNCO}]$ to [CO], normalized to their initial values, during a representative side-stream cigarette smoke $\mathrm{OH}$ oxidation and UV-B light control. The vertical black line indicates the time at which exposure to $\mathrm{OH}$ radical and light began. (B) Average percent increase of $[\mathrm{HNCO}] /[\mathrm{CO}]$ in chamber experiments after 30,60 , and 90 minutes of exposure to $\mathrm{OH}$ oxidation $(\mathrm{n}=6)$, UV-B light $(\mathrm{n}=1)$, indoor fluorescent light $(\mathrm{n}=2)$, and $\mathrm{O}_{3}$ oxidation $(n=4)$. Error bars show 1 standard deviation.

$\mathrm{HNCO}$ has been shown to be a product of amine, amide, and specifically nicotine oxidation by $\mathrm{OH}$ radicals in previous studies. ${ }^{22-24}$ Nicotine and other amines present in side-stream cigarette smoke $e^{46,47}$ are likely sources of the secondary production of HNCO observed here. The combination of reactive amines in cigarette smoke and their reaction products could account for the sustained $\mathrm{HNCO}$ production throughout $\mathrm{OH}$ oxidation. For example formamide, a major $\mathrm{OH}$ oxidation product of nicotine and precursor to $\mathrm{HNCO},{ }^{23,24,48}$ was measured by PTR-MS in selected $\mathrm{OH}$ oxidation of cigarette smoke experiments (section S3). Formamide was observed to form with $\mathrm{OH}$ oxidation and then react away slowly with further oxidation (Figure S1).

Formamide would have a chemical lifetime of over 300 minutes at the $\mathrm{OH}$ concentration used in the chamber study, consistent with the observation that HNCO precursors are available throughout the $\mathrm{OH}$ oxidation experiment and likely for longer than the measurement time (Figure 1A). While nicotine was not directly measured in this experiment, past side-stream cigarette smoke chamber experiments have measured the loss of nicotine with $\mathrm{OH}$ oxidation leading to formamide and HNCO production. ${ }^{40}$ Other sources of amines and amides indoors, such as from polymers, pharmaceuticals, surfactants, and cooking emissions may also produce $\mathrm{HNCO}$ with $\mathrm{OH}$ oxidation in indoor environments. 
A

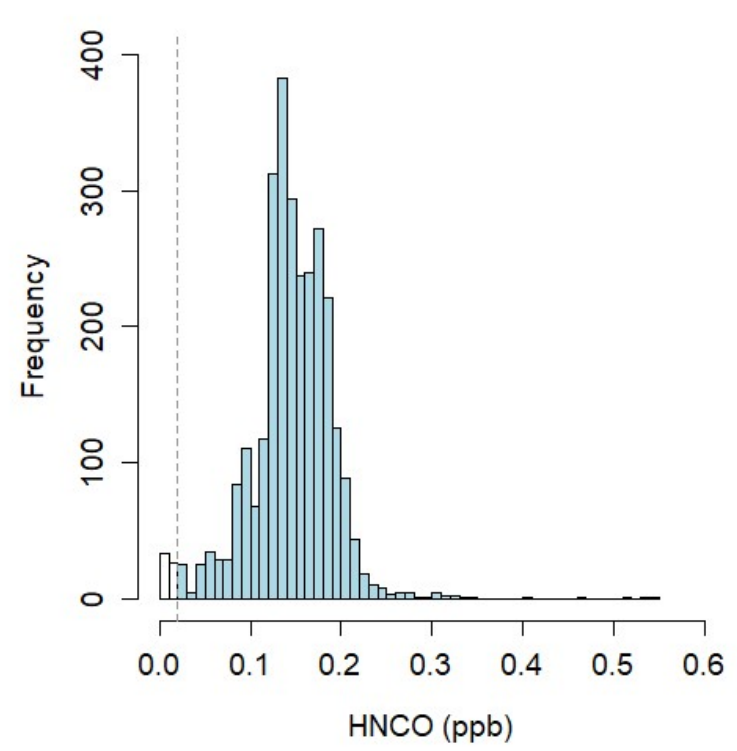

B

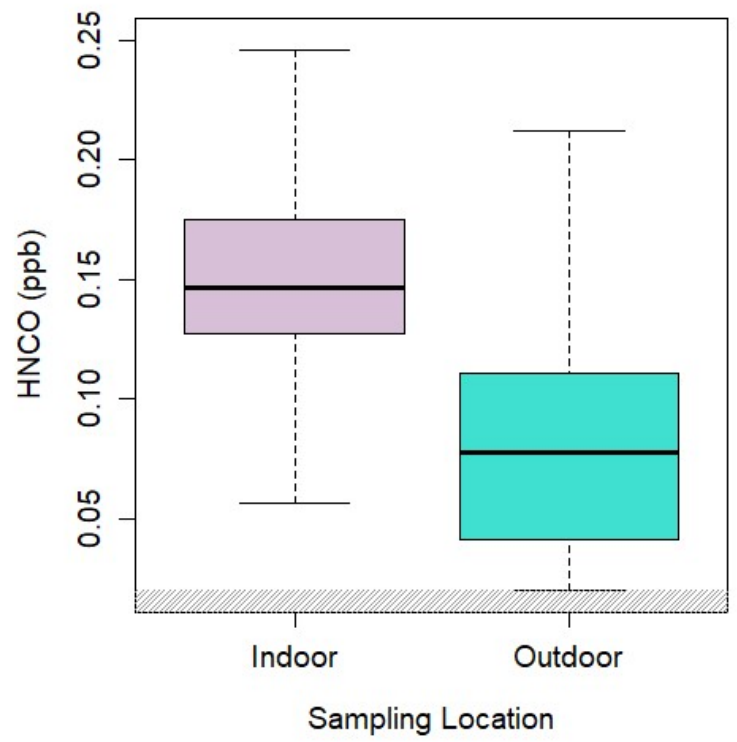

221

222

223

224

225

Figure 2. (A) Histogram of HNCO mixing ratio measured indoors and (B) box-and-whisker plot of HNCO mixing ratios comparing indoor and outdoor measurements at the Toronto residence. The median is shown as a thick line, the extent of the box shows the $25^{\text {th }}$ and $75^{\text {th }}$ percentiles, and the whiskers show the $5^{\text {th }}$ and $95^{\text {th }}$ percentiles. Dotted line (A) or shaded region (B) indicates limit of detection. All data are reported for non-experimental periods (i.e. not during cigarette burning periods).

To evaluate the environmental significance of the laboratory experiments, online measurements of HNCO were carried out in the Toronto residence in November 2016. Even prior to cigarette smoking experiments in this previosuly non-smoking residence, HNCO was consistently detected indoors during the measurement period. The indoor $\mathrm{HNCO}$ mixing ratio ranged from below the detection limit ( $0.02 \mathrm{ppb}$ ) to $0.55 \mathrm{ppb}$ (Figure 2A). HNCO's median mixing ratio indoors $(0.15 \mathrm{ppb})$ was greater compared to the median mixing ratio outdoors $(0.08 \mathrm{ppb})$ (Figure 2B). Nonetheless, this comparison was variable and subject to pertubations from activities in the house. Frequent switching between measurement of the indoor and outdoor air revealed that for the majority of the measurement period the indoor HNCO mixing ratios were elevated by a factor of approximately 2 . The range of HNCO measurements during the study period are 
summarized in Table S1. These measurements provide evidence for a consistent source of HNCO indoors, even before smoking had ever occurred in the residence.

Diurnal variations of HNCO mixing ratio for outdoor and indoor measurements are shown in Figures S2 and S3, respectively. The outdoor median HNCO mixing ratio remained below 0.1 ppb for the majority of the day, except for a peak between $8-11$ am local time, possibly due to traffic or local emissions. ${ }^{8,49,50}$ Inside the residence, the median HNCO mixing ratio was consistently greater than $0.1 \mathrm{ppb}$ with some indication of elevated mixing ratio between 9 am -6 pm local time, although there is variability in the diurnal profile. This temporal behaviour has been observed outdoors and attributed to photochemical production of $\mathrm{HNCO},{ }^{6,18,19}$ however the residence in our study did not have sufficient photon flux available to drive photochemistry indoors. We speculate that the increase of $\mathrm{HNCO}$ during the day could be due to increased temperature driving partitioning from the surfaces in the residence (see detailed descussion in section S5).

\section{HNCO emission from side-stream cigarette smoke indoors}

HNCO emission from combustion activities was investigated in the Toronto residence including candle burning, use of the gas stove, and cigarette smoking. Interestingly, the candle burning and stove use had no measurable effect on HNCO mixing ratios. During cigarette smoking experiments in the Toronto residence, the indoor HNCO mixing ratio increased by up to 10 times, peaking at the end of the smoking period (at 5 minutes). Once the cigarette was extinguished, the HNCO mixing ratio decreased rapidly. Emission of carbon monoxide during the smoking experiment followed a similar trend. A representative smoking experiment in the residence is shown in Figure 3.

HNCO emission ratios were calculated from data collected during smoking of the cigarette. Since there is variability in the emissions with each cigarette and burning conditions, an average of all cigarette burns $(n=6)$ was taken to determine an overall emission ratio of $2.0( \pm 0.6) \times 10^{-3}$ ppb $\mathrm{HNCO} / \mathrm{ppb} \mathrm{CO}$. As expected, similar emission ratios were determined for the cigarette smoke in the Toronto residence and the chamber experiments (Table 1).

The loss of $\mathrm{HNCO}$ after extinguishing the cigarette initially showed a similar rate of decay to that of $\mathrm{CO}$; however, approximately 10 minutes after the start of the experiment it was observed 
that the loss rate of $\mathrm{HNCO}$ is in fact faster than that of CO. Double exponentials were used to fit the HNCO and CO decay curves, which gave two characteristic lifetimes $(\tau)$ shown in Figure 3 (see section S6 and Figure S4 for details on fit). The first lifetimes of HNCO and CO were determined to be 2.2 and 2.8 minutes, respectively (Figure S5 and Table S2). This fast loss of both gases is likely reflective of the intrazonal mixing (within the kitchen), and interzonal mixing (from the kitchen area into the rest of the house). The interzonal mixing process in this residence was described in Collins et al. ${ }^{31}$

The second lifetimes of $\mathrm{HNCO}$ and $\mathrm{CO}$ were determined to be 14 and 52 minutes, respectively. The second lifetime of $\mathrm{CO}$ (52 minutes) is on the same order of magnitude as the air exchange rate of the residence during the measurement period, as described in Collins et al. ${ }^{31}$ This result indicates that the major loss pathway of $\mathrm{CO}$, other than mixing into the house, is exchange with outdoor air. The significantly faster loss $(\mathrm{p}<0.05)$ of HNCO compared to $\mathrm{CO}$ in the residence indicates that loss of $\mathrm{HNCO}$ is determined by processes in addition to dilution and mixing into the volume of the residence and exchange with outdoor air. Given its long gas-phase oxidation lifetime, it is most likely that HNCO partitions to or reacts at the surfaces within the house, providing an additional loss pathway.

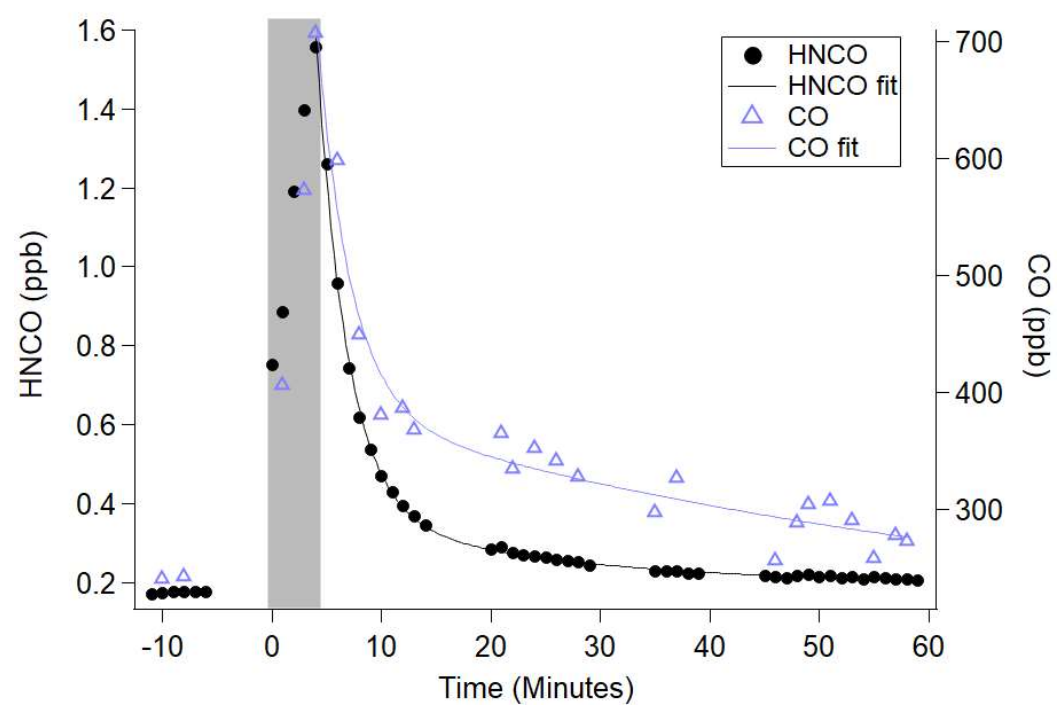

Figure 3. $\mathrm{HNCO}$ (black circles) and $\mathrm{CO}$ (purple triangles) mixing ratios during a cigarette smoking event in the Toronto residence. The shaded region indicates the time range when the cigarette was being smoked, beginning at time $=0$ minutes. Double exponential fits to the data after the cigarette is extinguished are used to determine lifetimes. 


\section{Evidence for secondary HNCO chemistry indoors}

289

290

291

292

293

294

295

296

297

298

299

300

301

302

303

304

305

306

307

308

309

310

311

312

313

314

315

316

The fast decay of HNCO following the large emission from cigarette smoking (Figure 3) indicated gas-surface partitioning of HNCO in the Toronto residence. Combustion sources, like smoking, can increase the abundance of HNCO and other semi-volatile or reactive gases on surfaces, which can act as a reservoir and source of these compounds when gas-phase concentrations decline.

Further evidence for a surface reservoir and partitioning of HNCO in the residence was shown in the elevated median HNCO mixing ratio during the daytime in the indoor diurnal profile (Figure S3). This observation indicates that secondary production of HNCO may occur indoors. The elevated daytime mixing ratio could be driven by a change in gas-surface partitioning of HNCO or precursor species with higher daytime temperatures (Section S5). In addition to temperature, partitioning of $\mathrm{HNCO}$ on indoor surfaces may also be affected by a change in $\mathrm{pH} .{ }^{51,52}$ Similarly, a surface reservoir for nitrous acid (HONO) that undergoes gas-surface partitioning was required to explain gas-phase HONO mixing ratios in this residence. ${ }^{31}$ Evidence for gas-surface partitioning of organic compounds, such as formaldehyde, ${ }^{53}$ has also been identified indoors.

Secondary production of HNCO from $\mathrm{OH}$ oxidation was not directly observed during the study in the Toronto residence. In particular, the ratio of $\mathrm{HNCO}$ to a conservative tracer species (i.e. $\mathrm{CO}$ ) decreased after cigarette burning (Figure 3); photochemical production of HNCO would have led to an increase instead. Indoors, $\mathrm{OH}$ production is dominated by nitrous acid (HONO) photolysis and alkene ozonolysis. ${ }^{54,55}$ Low light intensity from the small number of windows in the sampling location and the time of year (November), as well as low ozone mixing ratios $(90 \%$ of measurements $<13 \mathrm{ppb}$ ) likely limited the production of $\mathrm{OH}$. We observed no correlation of $\mathrm{HNCO}$ mixing ratio with $\mathrm{O}_{3}$ during the study, consistent with chamber experiments. Based on the measurements of cigarette smoke oxidation in the environmental chamber (Figure 1), further emission of secondary $\mathrm{HNCO}$ would occur in an indoor environment when higher $\mathrm{OH}$ concentrations are present.

\section{Conclusions}

Side-stream cigarette smoke emissions were investigated in an environmental chamber as well as in a Toronto residence in November 2016. The results from both settings demonstrated a 
significant primary source of $\mathrm{HNCO}$, with the emission of one cigarette increasing the $\mathrm{HNCO}$ mixing ratio by a factor of 10 in the residence. HNCO emission ratios were determined to be 2.7 $\times 10^{-3}$ and $2.0 \times 10^{-3} \mathrm{ppb} \mathrm{HNCO} / \mathrm{ppb} \mathrm{CO}$ for the chamber and the residence, respectively.

Secondary production of $\mathrm{HNCO}$ was demonstrated to occur with $\mathrm{OH}$ oxidation of side-stream cigarette smoke in the environmental chamber. This occurs via oxidation of precursor compounds such as nicotine and formamide. Cigarette smoke oxidation by $\mathrm{O}_{3}$ or photo-reaction under indoor fluorescent lights did not produce measurable HNCO. No evidence for photochemical production was observed in the house after cigarette burning, most likely because the low light intensity and low ozone mixing ratio limited the indoor $\mathrm{OH}$ concentration.

Notably, even before cigarette smoke was introduced to the residence, HNCO was at consistently elevated mixing ratios indoors compared to concurrent measurements of outdoor air. The source of $\mathrm{HNCO}$ under these conditions could be due to emission or partitioning from materials or surfaces within the residence or from slow oxidation of precursors, such as amines and amides. Faster loss of HNCO in the Toronto residence immediately after smoking compared to CO further indicated the occurence of partitioning or reaction at surfaces, acting as an additional loss pathway of HNCO. Previously undetermined sources of indoor HNCO described in this study from gas-surface partitioning, side-stream cigarette smoke, and $\mathrm{OH}$ oxidation of smoke - may pose a health risk to the occupants and should be investigated further to better understand the variety of potential sources within different types of indoor environments.

\section{Acknowledgements}

We acknowledge funding support for this work provided by the Alfred P. Sloan Foundation (Chemistry of Indoor Environments program) and Natural Sciences and Engineering Research Council of Canada (NSERC).

\section{References}

1 K. M. Hansson, J. Samuelsson, C. Tullin and L. E. Åmand, Formation of HNCO, HCN, and NH3 from the pyrolysis of bark and nitrogen-containing model compounds, Combust. Flame, 2004, 137, 265-277.

2 P. Veres, J. M. Roberts, I. R. Burling, C. Warneke, J. de Gouw and R. J. Yokelson, 
Measurements of gas-phase inorganic and organic acids from biomass fires by negativeion proton-transfer chemical-ionization mass spectrometry, J. Geophys. Res. Atmos., 2010, $115,1-15$.

J. M. Roberts, P. Veres, C. Warneke, J. A. Neuman, R. A. Washenfelder, S. S. Brown, M. Baasandorj, J. B. Burkholder, I. R. Burling, T. J. Johnson, R. J. Yokelson and J. de Gouw, Measurement of $\mathrm{HONO}, \mathrm{HNCO}$, and other inorganic acids by negative-ion proton-transfer chemical-ionization mass spectrometry (NI-PT-CIMS): Application to biomass burning emissions, Atmos. Meas. Tech., 2010, 3, 981-990.

J. M. Roberts, P. R. Veres, A. K. Cochran, C. Warneke, I. R. Burling, R. J. Yokelson, B. Lerner, J. B. Gilman, W. C. Kuster, R. Fall and J. de Gouw, Isocyanic acid in the atmosphere and its possible link to smoke-related health effects., Proc. Natl. Acad. Sci., 2011, 108, 8966-71.

J. B. Gilman, B. M. Lerner, W. C. Kuster, P. D. Goldan, C. Warneke, P. R. Veres, J. M. Roberts, J. A. de Gouw, I. R. Burling and R. J. Yokelson, Biomass burning emissions and potential air quality impacts of volatile organic compounds and other trace gases from fuels common in the US, Atmos. Chem. Phys., 2015, 15, 13915-13938.

V. Kumar, B. P. Chandra and V. Sinha, Large unexplained suite of chemically reactive compounds present in ambient air due to biomass fires, Sci. Rep., 2018, 8, 626. in the N.W. Indo-Gangetic Plain to ambient carcinogenic benzenoids, toxic isocyanic acid and carbon monoxide, Environ. Int., 2016, 88, 187-197.

J. J. B. Wentzell, J. Liggio, S. Li, A. Vlasenko, R. Staebler, G. Lu, M.-J. Poitras, T. Chan and J. R. Brook, Measurements of Gas phase Acids in Diesel Exhaust: A Relevant Source of HNCO?, Environ. Sci. Technol., 2013, 47, 7663-7671.

J. M. Brady, T. A. Crisp, S. Collier, T. Kuwayama, S. D. Forestieri, Q. Zhang, M. J. Kleeman, C. D. Cappa and T. H. Bertram, Real-Time Emission Factor Measurements of Isocyanic Acid from Light Duty Gasoline Vehicles, Environ. Sci. Technol., 2014, 48, 11405-11412. 
37310 M. F. Link, B. Friedman, R. Fulgham, P. Brophy, A. Galang, S. H. Jathar, P. Veres, J. R.

374 Roberts and D. K. Farmer, Photochemical processing of diesel fuel emissions form a large secondary source of isocyanic acid (HNCO), Geophys. Res. Lett., 2016, 43, 4033-4041.

R. Suarez-Bertoa and C. Astorga, Isocyanic acid and ammonia in vehicle emissions, Transp. Res. Part D, 2016, 49, 259-270.

D. Karlsson, M. Dalene, G. Skarping and Å. Marand, Determination of isocyanic acid in air, J. Environ. Monit., 2001, 3, 432-436.

13 C. J. Sennbro, C. H. Lindh, A. Östin, H. Welinder, B. A. G. Jönsson and H. Tinnerberg, A survey of airborne isocyanate exposure in 13 Swedish polyurethane industries, Ann. Occup. Hyg., 2004, 48, 405-414.

M. J. Jankowski, R. Olsen, C. J. Nielsen, Y. Thomassen and P. Molander, The applicability of proton transfer reaction-mass spectrometry (PTR-MS) for determination of isocyanic acid (ICA) in work room atmospheres, Environ. Sci. Process. Impacts, 2014, 16, 2423-2431.

M. J. Jankowski, R. Olsen, Y. Thomassen and P. Molander, The stability and generation pattern of thermally formed isocyanic acid (ICA) in air - potential and limitations of proton transfer reaction-mass spectrometry (PTR-MS) for real-time workroom atmosphere measurements, Environ. Sci. Process. Impacts, 2016, 18, 810-818.

J. M. Roberts, P. R. Veres, T. C. Vandenboer, C. Warneke, M. Graus, E. J. Williams, B. Dubé and J. A. de Gouw, New insights into atmospheric sources and sinks of isocyanic acid, HNCO, from recent urban and regional observations, J. Geophys. Res. Atmos., 2014, 119, 1060-1072.

R. Woodward-Massey, Y. M. Taha, S. G. Moussa and H. D. Osthoff, Comparison of negative-ion proton-transfer with iodide ion chemical ionization mass spectrometry for quantification of isocyanic acid in ambient air, Atmos. Environ., 2014, 98, 693-703. 
401

402

403

404

405

406

407

408

409

410

411

412

413

414

415

416

417

418

419

420

421

422

423

424

425

426

427

428

Bertram, L. N. Hawkins, J. P. D. Abbatt and J. Liggio, Cloud partitioning of isocyanic acid (HNCO) and evidence of secondary source of HNCO in ambient air, Geophys. Res. Lett., 2014, 41, 6962-6969.

19 C. Sarkar, V. Sinha, V. Kumar, M. Rupakheti, A. Panday, K. S Mahata, D. Rupakheti, B. Kathayat and M. G Lawrence, Overview of VOC emissions and chemistry from PTRTOF-MS measurements during the SusKat-ABC campaign: High acetaldehyde, isoprene and isocyanic acid in wintertime air of the Kathmandu Valley, Atmos. Chem. Phys., 2016, 16, 3979-4003.

20 J. Liggio, C. A. Stroud, J. J. B Wentzell, J. Zhang, J. Sommers, A. Darlington, P. S. K Liu, S. G. Moussa, A. Leithead, K. Hayden, R. L. Mittermeier, R. Staebler, M. Wolde and S.M. Li, Quantifying the Primary Emissions and Photochemical Formation of Isocyanic Acid Downwind of Oil Sands Operations, Environ. Sci. Technol., 2017, 51, 14462-14471.

21 I. Barnes, G. Solignac, A. Mellouki and K. H. Becker, Aspects of the atmospheric chemistry of amides, ChemPhysChem, 2010, 11, 3844-3857.

22 N. Borduas, J. P. D. Abbatt and J. G. Murphy, Gas Phase Oxidation of Monoethanolamine (MEA) with OH Radical and Ozone: Kinetics, Products, and Particles, Environ. Sci. Technol., 2013, 47, 6377-6383.

23 N. Borduas, G. Da Silva, J. G. Murphy and J. P. D. Abbatt, Experimental and theoretical understanding of the gas phase oxidation of atmospheric amides with $\mathrm{OH}$ radicals: Kinetics, products, and mechanisms, J. Phys. Chem. A, 2015, 119, 4298-4308.

24 N. Borduas, J. G. Murphy, C. Wang, G. da Silva and J. P. D. Abbatt, Gas Phase Oxidation of Nicotine by OH Radicals: Kinetics, Mechanisms, and Formation of HNCO, Environ. Sci. Technol. Lett., 2016, 3, 327-331.

25 N. Borduas, J. P. D. Abbatt, J. G. Murphy, S. So and G. Da Silva, Gas-Phase Mechanisms of the Reactions of Reduced Organic Nitrogen Compounds with OH Radicals, Environ. Sci. Technol., 2016, 50, 11723-11734.

26 M. Leslie, M. Ridoli, J. Murphy and N. Borduas-Dedekind, Isocyanic acid (HNCO) and its fate in the atmosphere: A review, Environ. Sci. Process. Impacts, 2019, 
27 L. M. Petrick, A. Svidovsky and Y. Dubowski, Thirdhand Smoke: Heterogeneous Oxidation of Nicotine and Secondary Aerosol Formation in the Indoor Environment, Environ. Sci. Technol., 2011, 45, 328-333.

28 L. M. Petrick, M. Sleiman, Y. Dubowski, L. A. Gundel and H. Destaillats, Tobacco smoke aging in the presence of ozone: A room-sized chamber study, Atmos. Environ., 2011, 45, 4959-4965.

29 C. Wang, D. B. Collins, R. F. Hems, N. Borduas, M. Antiñolo and J. P. D. Abbatt, Exploring Conditions for Ultrafine Particle Formation from Oxidation of Cigarette Smoke in Indoor Environments, Environ. Sci. Technol., 2018, 52, 4623-4631.

30 C. Wright, Standardized methods for the regulation of cigarette-smoke constituents, Trends Anal. Chem., 2015, 66, 118-127.

31 D. B. Collins, R. F. Hems, S. Zhou, C. Wang, E. Grignon, M. Alavy, J. A. Siegel and J. P. D. Abbatt, Evidence for Gas-Surface Equilibrium Control of Indoor Nitrous Acid, Environ. Sci. Technol., 2018, 52, 12419-12427.

32 E. N. Escorcia, S. J. Sjostedt and J. P. D. Abbatt, Kinetics of N2O5 Hydrolysis on Secondary Organic Aerosol and Mixed Ammonium Bisulfate-Secondary Organic Aerosol Particles, J. Phys. Chem. A, 2010, 114, 13113-12121.

33 P. Brophy and D. K. Farmer, Clustering, methodology, and mechanistic insights into acetate chemical ionization using high-resolution time-of-flight mass spectrometry, Atmos. Meas. Tech., 2016, 9, 3969-3986.

34 D. Aljawhary, A. K. Y. Lee and J. P. D. Abbatt, High-resolution chemical ionization mass spectrometry (ToF-CIMS): Application to study SOA composition and processing, Atmos. Meas. Tech., 2013, 6, 3211-3224.

35 R. Zhao, E. L. Mungall, A. K. Y. Lee, D. Aljawhary and J. P. D. Abbatt, Aqueous-phase photooxidation of levoglucosan - a mechanistic study using Aerosol Time of Flight Chemical Ionization Mass Spectrometry (Aerosol-ToF-CIMS), Atmos. Chem. Phys., 2014, 14, 9695-9706. 
457

458

459

460

461

462

463

464

465

466

467

468

469

470

471

472

473

474

475

476

477

478

479

480

481

482

483

484

36 E. L. Mungall, B. Croft, M. Lizotte, J. L. Thomas, J. G. Murphy, M. Levasseur, R. V. Martin, J. J. B. Wentzell, J. Liggio and J. P. D. Abbatt, Dimethyl sulfide in the summertime Arctic atmosphere: Measurements and source sensitivity simulations, Atmos. Chem. Phys., 2016, 16, 6665-6680.

37 D. Aljawhary, R. Zhao, A. K. Y. Lee, C. Wang and J. P. D. Abbatt, Kinetics, Mechanism, and Secondary Organic Aerosol Yield of Aqueous Phase Photo-oxidation of $\alpha$-Pinene Oxidation Products, J. Phys. Chem. A, 2016, 120, 1395-1407.

38 R. Zhao, D. Aljawhary, A. K. Y. Lee and J. P. D. Abbatt, Rapid Aqueous-Phase Photooxidation of Dimers in the $\alpha$-Pinene Secondary Organic Aerosol, Environ. Sci. Technol. Lett., 2017, 4, 205-210.

39 A. R. Koss, K. Sekimoto, J. B. Gilman, V. Selimovic, M. M. Coggon, K. J. Zarzana, B. Yuan, B. M. Lerner, S. S. Brown, J. L. Jimenez, J. Krechmer, J. M. Roberts, C. Warneke, R. J. Yokelson and J. de Gouw, Non-methane organic gas emissions from biomass burning: identification, quantification, and emission factors from PTR-ToF during the FIREX 2016 laboratory experiment, Atmos. Chem. Phys., 2018, 18, 3299-3319.

40 N. Borduas, The atmospheric fate of organic nitrogen compounds, $\mathrm{PhD}$ thesis, University of Toronto, 2015.

41 F. P. Tully, R. A. Perry, L. R. Thorne and M. D. Allendorf, Free-radical oxidation of isocyanic acid, Symp. Combust., 1989, 22, 1101-1106.

42 W. Tsang, Chemical Kinetic Data Base for Propellant Combustion. II. Reactions Involving CN, NCO, and HNCO, J. Phys. Chem. Ref. Data, 1992, 21, 753-791.

43 I. R. White, D. Martin, M. P. Muñoz, F. K. Petersson, S. J. Henshaw, G. Nickless, G. C. Lloyd-Jones, K. C. Clemitshaw and D. E. Shallcross, Use of Reactive Tracers To Determine Ambient OH Radical Concentrations: Application within the Indoor Environment, Environ. Sci. Technol., 2010, 44, 6269-6274.

44 N. Carslaw, L. Fletcher, D. Heard, T. Ingham and H. Walker, Significant OH production under surface cleaning and air cleaning conditions: Impact on indoor air quality, Indoor Air, 2017, 27, 1091-1100. 

Combustion processes as a source of high levels of indoor hydroxyl radicals through the photolysis of nitrous acid, Environ. Sci. Technol., 2015, 49, 6599-6607.

46 R. L. Stedman, The Chemical Composition of Tobacco and Tobacco Smoke, Chem. Rev., $1968,68,158-207$.

47 M. Sleiman, J. M. Logue, W. Luo, J. F. Pankow, L. A. Gundel and H. Destaillats, Inhalable Constituents of Thirdhand Tobacco Smoke: Chemical Characterization and Health Impact Considerations, Environ. Sci. Technol., 2014, 48, 13093-13101.

48 A. J. C. Bunkan, T. Mikoviny, C. J. Nielsen, A. Wisthaler and L. Zhu, Experimental and Theoretical Study of the OH-Initiated Photo-oxidation of Formamide, J. Phys. Chem. A, 2016, 120, 1222-1230.

49 S. H. Jathar, C. Heppding, M. F. Link, D. K. Farmer, A. Akherati, M. J. Kleeman, J. A. de Gouw, P. R. Veres and J. M. Roberts, Investigating diesel engines as an atmospheric source of isocyanic acid in urban areas, Atmos. Chem. Phys., 2017, 17, 8959-8970.

50 S. N. Wren, J. Liggio, Y. Han, K. Hayden, G. Lu, C. M. Mihele, R. L. Mittermeier, C. Stroud, J. J. B. Wentzell and J. R. Brook, Elucidating real-world vehicle emission factors from mobile measurements over a large metropolitan region: a focus on isocyanic acid, hydrogen cyanide, and black carbon, Atmos. Chem. Phys, 2018, 18, 16979-17001.

51 N. Borduas, B. Place, G. R. Wentworth, J. P. D. Abbatt and J. G. Murphy, Solubility and reactivity of $\mathrm{HNCO}$ in water: Insights into HNCO's fate in the atmosphere, Atmos. Chem. Phys., 2016, 16, 703-714.

52 J. M. Roberts and Y. Liu, Solubility and Solution-phase Chemistry of Isocyanic Acid, Methyl Isocyanate, and Cyanogen Halides, Atmos. Chem. Phys. Discuss., 2018, in review.

53 J. N. Pitts Jr., H. W. Biermann, E. C. Tuazon, M. Green, W. D. Long and A. M. Winer, Time-resolved Identification and Measurement of Indoor Air Pollutants by Spectroscopic Techniques: Gaseous Nitrous Acid, Methanol, Formaldehyde and Formic Acid, JAPCA, 1989, 39, 1344-1347. 
51354 E. Gómez Alvarez, D. Amedro, C. Afif, S. Gligorovski, C. Schoemaecker, C. Fittschen,

514 J.-F. Doussin and H. Wortham, Unexpectedly high indoor hydroxyl radical concentrations associated with nitrous acid, Proc. Natl. Acad. Sci., 2013, 110, 13294-13299.

51655 N. Carslaw, A new detailed chemical model for indoor air pollution, Atmos. Environ., $517 \quad 2007,41,1164-1179$. 


\section{Supporting Information for:}

Sources of isocyanic acid (HNCO) indoors: a focus on cigarette smoke

Rachel F. Hems,${ }^{\dagger}$ Chen Wang, ${ }^{\dagger}$ Douglas B. Collins, ${ }^{\ddagger}$ Shouming Zhou, ${ }^{\dagger}$ Nadine BorduasDedekind, Jeffrey A. Siegel, ${ }^{\star}$ Jonathan P.D. Abbatt* ${ }^{\dagger}$

${ }^{\dagger}$ Department of Chemistry, University of Toronto, 80 St. George Street, Toronto, Ontario M5S 3H6, Canada.

${ }^{ \pm}$Department of Civil and Mineral Engineering, University of Toronto, 35 Street George Street, Toronto, Ontario M5S 1A4, Canada.

${ }^{\ddagger}$ Department of Chemistry, Bucknell University, 1 Dent Drive, Lewisburg, PA 17837, USA.

* Corresponding Author Email: jonathan.abbatt@utoronto.ca

\section{S1. Calibration of HNCO}

\section{ToF-CIMS}

A source of gas phase isocyanic acid (HNCO) was produced by heating cyanuric acid $(98 \%$, Sigma-Aldrich) to $250^{\circ} \mathrm{C}$ in a stainless-steel flow cell with $200 \mathrm{sccm}$ of $\mathrm{N}_{2}$ passing over it, which decomposes to 3 molecules of HNCO. This flow was immediately diluted with $1700 \mathrm{sccm}$ of $\mathrm{N}_{2}$ to minimize polymerization. A second, adjustable dilution of zero air (Air grade zero 0.1; Linde [Canada], Inc.) was added downstream to vary the HNCO concentration. The HNCO flow was delivered to the CIMS inlet and to a bubbler filled with $30 \mathrm{~mL}$ of purified water $(18.2 \mathrm{M} \Omega \mathrm{cm})$ simultaneously for approximately $120 \mathrm{~min}$. The bubbler sample was diluted to $50 \mathrm{~mL}$ in a volumetric flask and used for external calibration by ion chromatography on the same day. Assuming that all $\mathrm{HNCO}$ was captured as $\mathrm{NCO}^{-}$in the water bubbler at a constant flow rate, the gas phase concentration of HNCO could be calculated. This assumption was verified by placing a second bubbler in sequence with the first, and confirmed no HNCO breakthrough.

The $\mathrm{NCO}^{-}(\mathrm{m} / \mathrm{z} 42.00)$ signal from the ToF-CIMS was first normalized by the reagent ion signal (acetate, $\mathrm{m} / \mathrm{z} 59.01$ ) and then background corrected by subtracting the signal during zero air measurement. 


\section{Ion Chromatography}

A Dionex Integrion HPIC system (ThermoFisher) was used for calibration of HNCO. A Dionex IonPac (AS19, 4×250 mm) anion analytical column with an AG19 guard column was used to resolve anions of interest. $5 \mathrm{~mL}$ samples were injected with a Dionex (AS-DV) autosampler and accumulated on a concentrator (Dionex IonPac TAC-ULP1), then flushed with potassium hydroxide eluent on to the column. A $1 \mathrm{~mL} / \mathrm{min}$ gradient elution of potassium hydroxide was used, starting at $1 \mathrm{mM}$, linearly increasing to $20 \mathrm{mM}$ over $12 \mathrm{~min}$, then linearly decreasing again to $1 \mathrm{mM}$ until $15 \mathrm{~min}$ to regenerate the initial conditions, with a total run time of $19 \mathrm{~min}$.

Calibrations of known isocyanate $\left(\mathrm{NCO}^{-}\right)$concentrations were prepared from serial dilutions of potassium isocyanate ( $96 \%$, Sigma-Aldrich).

A sensitivity of 0.0226 counts per second / ppb was determined for the ToF-CIMS measurement of HNCO.

Calibration of the Quad-CIMS was carried out in the same way as described above, following the chamber measurements. The sensitivity was determined to be 0.0037 counts per second / ppb.

\section{S2. Details of ToF-CIMS Data Analysis during measurements in the Toronto residence}

After processing the raw data in Tofware (Tofwerk, AG, Areodyne Research Inc. Version 2.5.7) on Igor Pro (WaveMetric Inc. Version 6.37), the high resolution data was exported and all further data analysis was completed in $\mathrm{R}^{1}$ using some functions from the package "open air". ${ }^{2}$ The $\mathrm{NCO}^{-}$signal $\left(\mathrm{m} / z\right.$ 42.00) was normalized to the $\mathrm{CH}_{3} \mathrm{COO}^{-}$reagent ion signal $(\mathrm{m} / \mathrm{z}$ 59.01) and was then background corrected by linearly interpolating between the hourly zero air measurements. Due to the non-instantaneous nature of the valve switching, data within 20 seconds on either side of a valve change (ie. changing sampling location) was disregarded. The limit of detection was determined, during the measurement period, by calculating 3 times the standard deviation during the zero air (background) measurements.

\section{S3. PTR-MS detection of formamide in chamber experiment}

A proton transfer reaction - mass spectrometer (PTR-MS, Ionicon Analytik GmbH, Innsbruck Austria) was used to determine the steady-state $\mathrm{OH}$ concentration during select 
chamber experiments, as described by Wang et al. ${ }^{3}$ This instrument can detect amines and amides present in the side-stream cigarette smoke. Figure S1 shows the signal at $m / z 46$, consistent with formamide $\left([\mathrm{M}+\mathrm{H}]^{+}\right)$, during a side-stream cigarette smoke $\mathrm{OH}$ oxidation experiment. The $m / z 46$ signal is presented as the ratio to [CO] (in ppb) to account for dilution in the chamber. Elapsed time $=0$ indicates the time $\mathrm{OH}$ oxidation was initiated, after cigarette smoke had already been introduced into the chamber. The signal for formamide was not significant in the primary cigarette smoke (before 0 minutes), but increases initially with $\mathrm{OH}$ oxidation followed by a slow decrease after 50 minutes had elapsed.

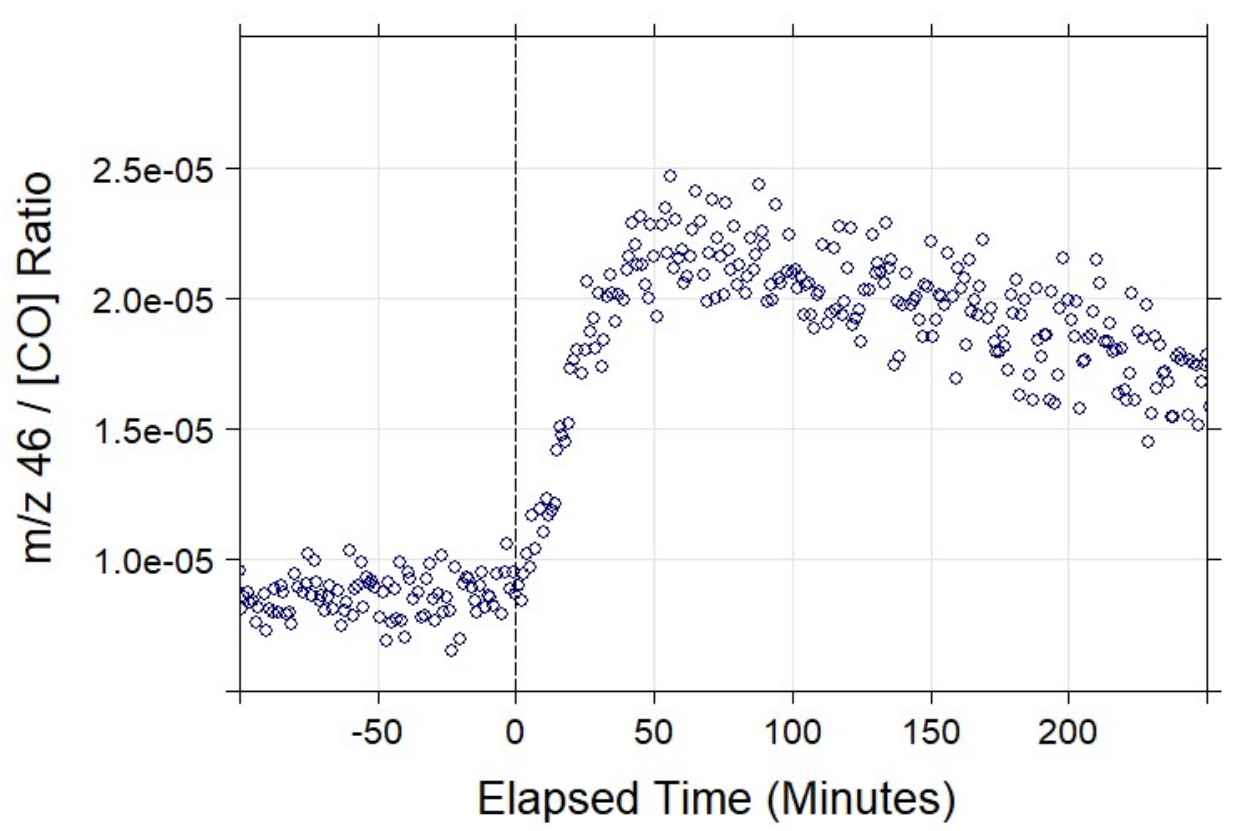

Figure S1. Ratio of signal at $\mathrm{m} / \mathrm{z} 46$ to [CO], during a representative side-stream cigarette smoke $\mathrm{OH}$ oxidation. The vertical line indicates the time at which exposure to $\mathrm{OH}$ began. 


\section{S4. HNCO Statistical Data - Measurements in the Toronto residence}

Table S1. Summary of HNCO measurements in the Toronto residence.

\begin{tabular}{|l|c|c|c|c|}
\hline $\begin{array}{l}\text { Sampling } \\
\text { Location }\end{array}$ & $\begin{array}{l}\text { Minimum } \\
{[\mathrm{HNCO}](\mathrm{ppb})}\end{array}$ & $\begin{array}{l}\text { Maximum } \\
{[\mathrm{HNCO}](\mathrm{ppb})}\end{array}$ & $\begin{array}{l}\text { Median } \\
{[\mathrm{HNCO}](\mathrm{ppb})}\end{array}$ & $\begin{array}{l}\text { Mean }[\mathrm{HNCO}] \\
(\mathrm{ppb})\end{array}$ \\
\hline Indoor & $<\mathbf{0 . 0 2}$ & $\mathbf{0 . 5 5}$ & $\mathbf{0 . 1 5}$ & $\mathbf{0 . 1 5}$ \\
\hline Outdoor & $<\mathbf{0 . 0 2}$ & $\mathbf{3 . 3}$ & $\mathbf{0 . 0 8}$ & $\mathbf{0 . 1 0}$ \\
\hline
\end{tabular}

\section{S5. Diurnal profiles of HNCO at Toronto Residence}

Diurnal plots for HNCO concentrations outdoors and indoors during the study period (compiled from 9 days of measurements) are shown in Figures S2 and S3, respectively. Outdoors, HNCO is highest in the morning (peaking between $8-11$ am local time), likely corresponding to morning traffic. The median concentration is lower throughout the day $(<$ $100 \mathrm{ppt}$ ) and does not show evidence for secondary production in the afternoon when photon flux is highest. Daylight hours during the study period were approximately between 7 am and $5 \mathrm{pm}$ local time. The diurnal profile of HNCO indoors (Figure S3) spans a much narrower range of mixing ratio, with less prominent variation over the day. There is some indication that the HNCO mixing ratio increases in the morning (beginning around 9 am local time) and remains higher throughout the day until approximately $6 \mathrm{pm}$ local time. The difference between the outdoor and indoor diurnal profiles of $\mathrm{HNCO}$ demonstrates that there are different sources of $\mathrm{HNCO}$ and that the indoor concentration is not merely dependent on outdoor concentration. While there is a large amount of variability in the indoor $\mathrm{HNCO}$ mixing ratio, the increased mixing ratio throughout the day could indicate that there is an impact of increased daytime temperature. This observation agrees with the hypothesis that $\mathrm{HNCO}$ can partition with surfaces inside the residence, since partitioning behaviour will be influenced by temperature. There is a weak, positive correlation between HNCO and temperature, with an $r$ value of 0.46 and $p<0.05$. 


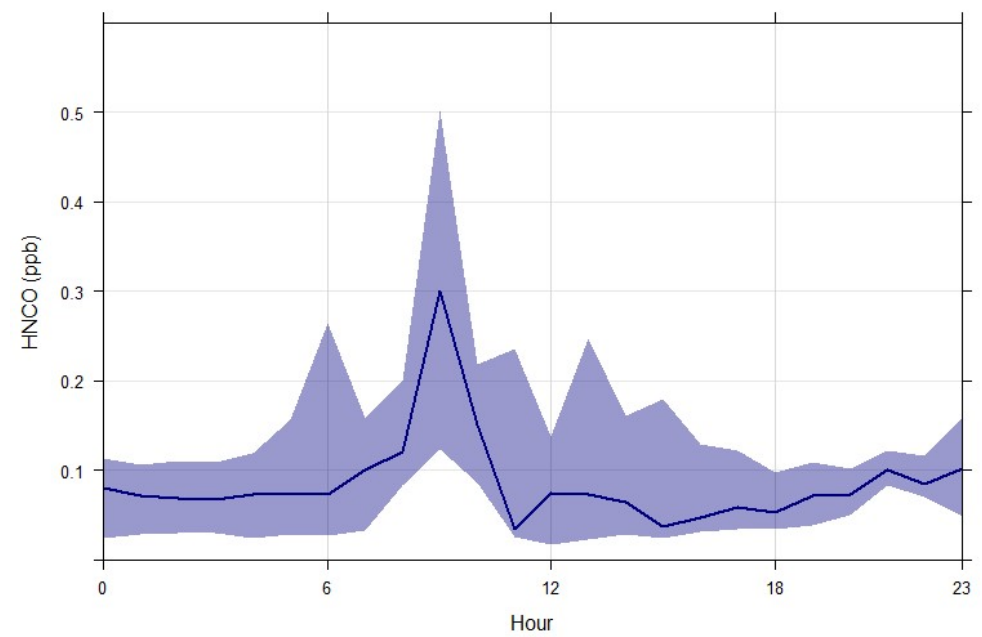

Figure S2. Diurnal plot of HNCO concentration outdoors at the Toronto residence for the duration of the measurement period. The line shows the median concentration, with shading indicating the $25^{\text {th }}$ and $75^{\text {th }}$ percentiles.

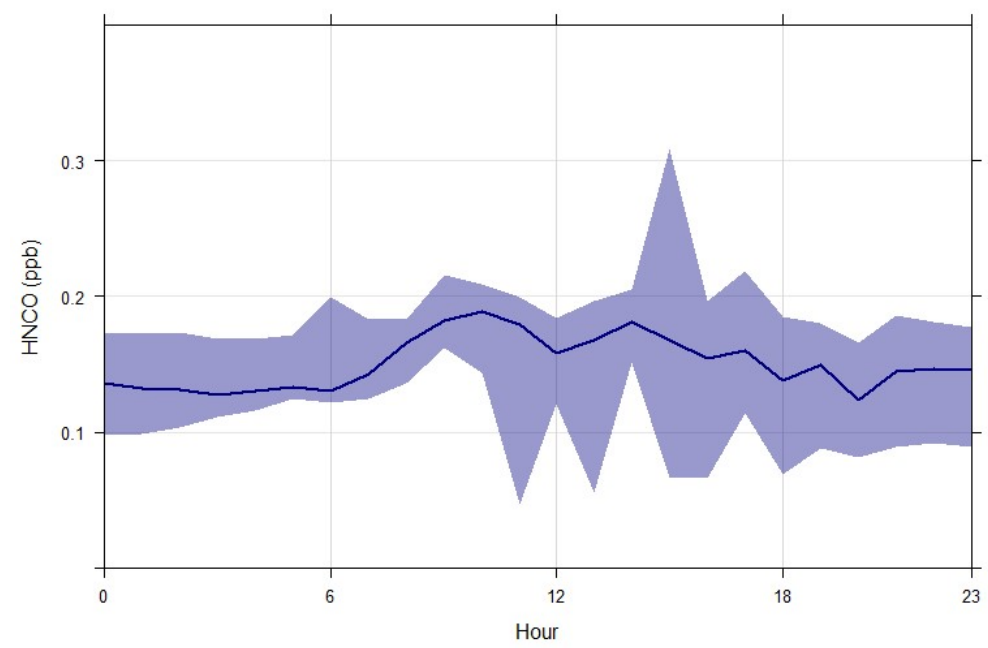

Figure S3. Diurnal plot of $\mathrm{HNCO}$ concentration inside the Toronto residence for the duration of the measurement period. The line shows the median concentration, with shading indicating the $25^{\text {th }}$ and $75^{\text {th }}$ percentiles. 
S6. Exponential fitting for HNCO and CO loss rate - Measurements in the Toronto Residence
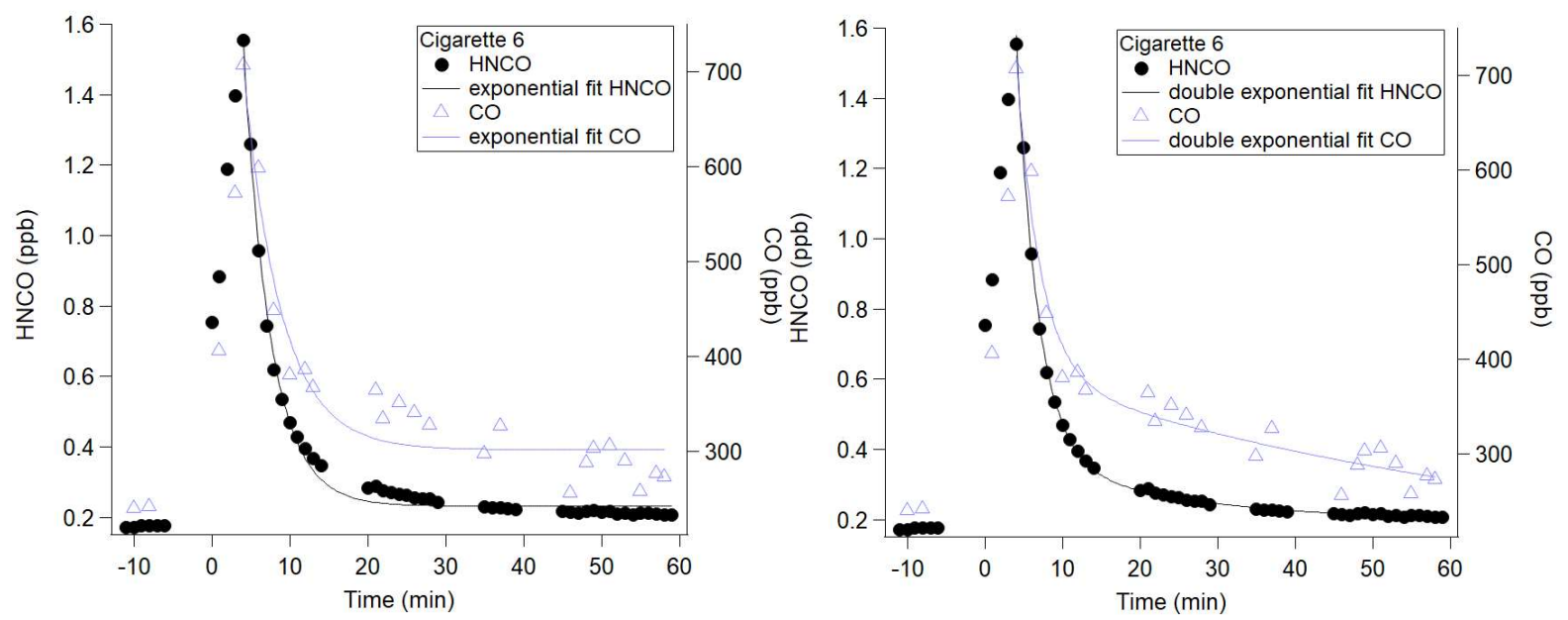

Figure S4. (A) Loss of [HNCO] and [CO] after cigarette is extinguished, fit with a single exponential equation for a representative cigarette experiment in the Toronto residence. (B) The same data as shown in (A) but fit with a double exponential equation.

\section{Lifetime $(\tau)$ Determination}

Exponential fits were examined only for the four cigarette experiments which had sufficient data immediately after the cigarette was extinguished. The two lifetime $(\tau)$ values, which were determined as the time-constant from the exponential fits, are reported below in Figure S5 and summarized in Table S2. 

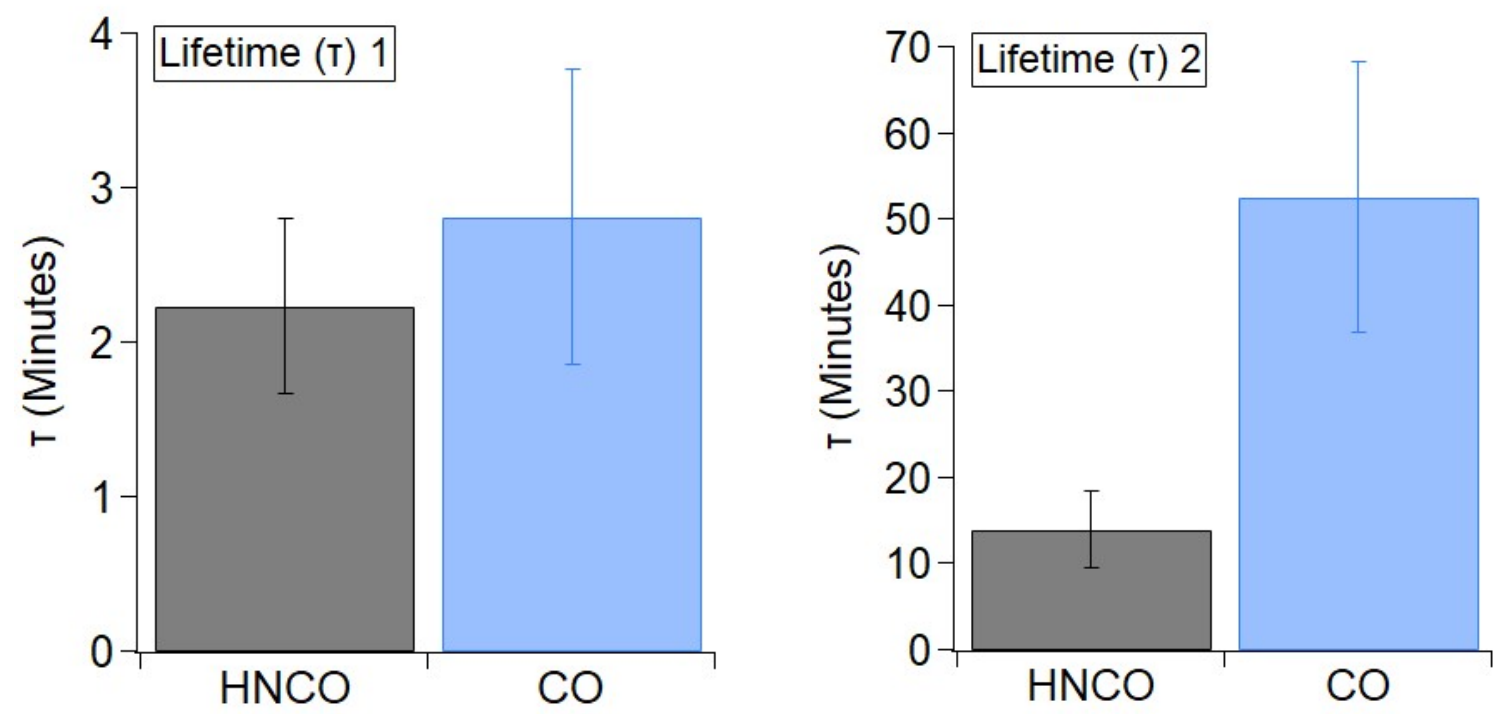

Figure S5. (A) The first lifetime $(\tau)$ determined from the exponential fit to the HNCO and CO loss following cigarette extinguishing. (B) The second lifetime $(\tau)$ determined from the same exponential fit.

Table S2. Summary of the lifetimes $(\tau)$ determined from the double exponential fits to the HNCO and CO loss data in the Toronto residence.

\begin{tabular}{|l|l|l|}
\hline Species & $\boldsymbol{\tau}$ 1 (Minutes) & $\boldsymbol{\tau} 2$ (Minutes) \\
\hline HNCO & $2.2 \pm 0.6$ & $14.0 \pm 4.4$ \\
\hline CO & $2.8 \pm 0.9$ & $52.5 \pm 15.8$ \\
\hline
\end{tabular}

\section{References}

1 R Core Team, R: A Language and Environment for Statistical Computing, R Foundation for Statistical Computing, Vienna, Austria, 2018.

2 D. C. Carslaw and K. Ropkins, Environ. Model. Softw., 2012, 27-28, 52-61.

3 C. Wang, D. B. Collins, R. F. Hems, N. Borduas, M. Antiñolo and J. P. D. Abbatt, Environ. Sci. Technol., 2018, 52, 4623-4631. 